\title{
Understanding the public debate about trophy hunting in China as a rural development mechanism
}

Xuehong Zhou'; Douglas C. MacMillan; Wei Zhang'; Qiang Wang ${ }^{3 *}$; Yuhui Jin; Diogo Verissimo 4

1 College of Wildlife and Protected Area, Northeast Forestry University, Harbin, Heilongjiang Province, 150040, China

2 Durrell Institute of Conservation and Ecology (DICE), University of Kent, Canterbury, Kent CT2 7NR, UK

3 Key Laboratory of Wetland Ecology and Environment, Northeast Institute of Geography and Agroecology, Chinese Academy of Sciences, Changchun, Jilin Province, 130102, China

4 Department of Zoology, University of Oxford, Zoology Research and Administration Building, 11a Mansfield Road, Oxford OX1 3SZ

* Corresponding author:

Name: Qiang Wang

Complete mailing address: No. 26, Hexing Road, Xiangfang District, Harbin, Heilongjiang, China 150040,

Telephone: +86 18646287517

E- mail: wangqiang_1978@126.com

\section{Abstract}

The use of trophy hunting as a wildlife management option has been a highly controversial topic, especially in southern Africa, but trophy hunting has historically also taken place also throughout Asia. In China, trophy hunting was the topic of 
intense public discussion more than a decade ago, leading ultimately to the suspension of this practice in 2006. Yet, this debate was dominated by urban voices, with no formal consultation of rural populations from minorities such as the Tibetan herders who previously benefited financially from commercial trophy hunting and who are concerned about the negative impaction of rising blue sheep numbers on livestock grazing. We used a discrete choice experiment econometric method to better understand the trade-offs made by both urban and rural populations across China in relation trophy hunting as a rural development and wildlife management tool. We find that trophy hunting is supported by the majority of rural residents but opposed by most urban residents, although there is heterogeneity within both of these groups. We recommend that policy-making in this realm should be informed by a better understanding of the preferences of different stakeholders, including the local people who bear the costs of living with wildlife.

\section{Keywords}

Wildlife conservation; Community participation; Sustainable development; Blue sheep; Ungulate; Tibet

\section{Introduction}

Trophy hunting is a form of managed hunting whereby specific animals are targeted for the primary purpose of harvesting body part(s) such as skin, antlers and head (Lindsey et al., 2016; Macdonald et al., 2016). Although the killing of the African Lion, 'Cecil' in 2015, outside Hwange National Park, Zimbabwe, initiated global mass outrage, trophy hunting has always been controversial from a range of ecological, ethical and cultural perspectives (Adams, 2009). While the potential negative impacts on population genetics, structure and demographics is well understood (Trenkle, 
2001; Crosmary et al., 2013; Wielgus et al., 2013), the killing of animals for entertainment and for body parts in exchange for high-fees by wealthy individuals, usually from outside the area where the hunting occurs is seen as both primitive and cruel by the growing animal rights and welfare movement (MacDonald et al., 2016) and as. Furthermore, this practice is often described as an anachronism redolent of medieval times that serves to reinforces inequities between the rights of rich and poor in rural areas (MacMillan, 2004). On the other hand, the benefits of trophy hunting present a way to generate largely focus on economic factors such as local employment, the maintenance of high land values (MacMillan et al., 2010) and downstream spending in the local economy (IUCN SSC, 2012). That enable rural landholders and local communities to tolerate, or even support, wildlife conservation on their land (MacMillan\&Leitch,2008).

The aim if this study is to explicitly explore the trade-offs between the pecuniary benefits of trophy hunting and animal welfare issues across a range of different socio-cultural groups in society. Our location of interest is China, the most populous country on the planet and where trophy hunting has in practice been banned since 2006 (Jiang et al., 2012; Cao, Zhou \& Zhang, 2014) due to public opposition from large metropolitan areas such as Beijing (Jiang et al., 2012). Our case study involves a potential proposal to reintroduce trophy hunting of the blue sheep (Pseudois nayaur), in Qinghai Province in western China.

In this province, blue sheep numbers and other herbivores such as Tibetan antelope, have increased dramatically due to conservation efforts, with the former being arguably the single most numerous species of large mammal in western China (NDRC, 1996; NEPA, 2002). This rapid population expansion has substantially impacted on the amount of grazing available to local herders, who are almost entirely dependent on domestic yak, sheep and goats for their livelihood (Harris, 2008; Heqin, 2016).

In the past, the Dulan International Hunting Area was the largest hunting area in 
China in terms of hunters and trophies (Harris, 2008). Local people benefited from additional revenues from acting as hunting guides, but also from improvements to local healthcare and transportation as well as the opportunity for intercultural exchange (Liu, 1993). Local communities and the government remain keen on reintroducing trophy hunting, both as a means of managing blue sheep numbers, but also as an important rural development measures (Wang, Zhang \& Zhang, 2006; Cao et al., 2014) but the proposal is controversial. An attempt to reintroduce hunting in 2011 was thwarted by a strong public backlash that led to main tourist operators withdrawing their application (Jiang et al., 2012).

In our research we use discrete choice experiments to explore preferences about the reintroduction of trophy hunting in China. Choice experiments is a quantitative survey-based technique that is increasingly being used to understand stakeholder trade-offs around conservation policies (Harihar, Veríssimo \& MacMillan, 2015; Subroy, Rogers \& Kragt, 2018) including trophy hunting (Bullock, Elston \& Chalmers, 1998). Unlike previous studies, which have targeted hunters and their willingness to pay for alternative hunting experiences, here we explore the trade-offs of benefits and costs between trophy hunting, blue sheep conservation and local livelihoods among the rural and urban audiences.

Different stakeholder values and attitudes influence policy support and acceptability, producing conflict over appropriate management interventions for wildlife (Brown et al. 2019). As such, we also explore how preferences diverge across different culturalethnic groupings (rural Tibetan and Mongol as well as urban Han). In this way we hope to understand the preferences of local communities, whom live alongside and suffer the related costs of co-existing with wildlife (Angula et al., 2018), and contrast them with urban residents, who have been fiercely critical of hunting yet who live many miles away from the conflict and thus do not bear the cost of living with wildlife (Macdonald et al., 2017). This is vital because the views of rural communities have hitherto been conspicuously absent from the public debate (Chaukura et al., 2020). 
Our research contributes evidence to the highly topical wider debate about the future role of trophy hunting in wildlife management and rural development (Bauer et al., 2019; Störmer et al., 2019). While previous research on trophy hunting has focused on sub-Saharan Africa (Naidoo et al., 2016; Störmer et al., 2019), we hope to showcase the unique context of the debate around trophy hunting in regions such as central Asia, where there is a history of trophy hunting (Cooney, 2017) and the challenges of funding conservation, in the absence of a large scale wildlife tourism industry as in many regions of Africa, are arguably, at least just as dire.

\section{Methods}

Our research focused on three locations. The first is Dulan International Hunting Area, Qinghai Province, where trophy hunting used to take place. This hunting area is located in Dulan county, a sparsely populated region of around 70000 inhabitants in 2016 (Qinghai Provincial Bureau of Statistics, 2017) mostly inhabited by seminomadic pastoralists of Mongol and Tibetan ethnic origin.

Dulan's hunting grounds are state-owned with all land being government owned. Local herders are able to lease land for pastures for a long period (commonly 50 years). As such the only community members that benefit from this activity are those, employed as guides or porters. According to "Wild Animal Conservation Law of the People's Republic of China" (2018), all other compensation or benefits are accrued via local government subsidies. Before stopping Chinese trophy hunting in 2006, trophy hunting income was an important source of compensation for villagers suffering from wildlife damage.

The second is Xining, the capital of Qinghai Province and the largest city in the Tibetan Plateau, with about 2.2 million inhabitants with a variety of ethnicities. The third is Beijing, capital of China, one of the largest urban areas in the world with about 27.3 million inhabitants, mainly of the majority Han ethnic group. 


\section{Survey design}

Our survey consisted of three sections. The first consisted of a number of questions about the demographics of the respondent including gender, age, income, education, household size, and, for respondents in Dulan, the number of goats, sheep and yak owned.

The second section contained five attitudinal statements (below) to score on a 5point Likert scale.

- We need to manage wildlife populations to prevent them from going extinct.

- We need to manage wildlife populations by hunting to prevent them significantly affecting livelihoods of traditional herders.

- A percentage of fees from hunting should be paid to the local communities to compensate them for reductions in income caused by wildlife.

- Blue sheep and other grazing wildlife should be totally protected without any management to control numbers.

- Trophy hunting is a sensible and sustainable approach to the management of Blue sheep and other grazing wildlife.

The third section focused on choice experiments. We aimed to keep the Choice Experiment design short, to minimize the cognitive burden and overall time spend on the questionnaire. This was especially important in rural areas when the experience of survey participation may be less familiar (VerÍssimo et al., 2014). Hence, we focused on three attributes of greatest relevance to the policy debate (Table 1).

- Trophy hunting: the wildlife management strategy that we wanted to better understand. We did not include here other activities such as ecotourism as that activity is not viable in that region due to the lack of access routes and infrastructure.

- Alternative population scenarios for blue sheep, which was a key species for trophy hunting in China. The numbers of this species are also a key indicator 
used by local wildlife managers which work to ensure populations remain viable. At the same time the species is a competitor for domestic livestock which means local herders would prefer keeping its numbers from growing. In terms of levels we choose to have a variation of $50 \%$ (with reference to the blue sheep population size at the time) as the upper and lower limit to explore trade-offs between species conservation and potential impacts on local livelihoods in the case of substantial variations in blue sheep populations. To this we added $10 \%$ variation (with reference to the blue sheep population size at the time) to explore whether small variations would be tolerated by different stakeholders.

- Subsidy paid by the government to herders sharing the landscape with the blue sheep - stronger support for the plan thereby indicated by higher subsidy. The Chinese context is different from locations in Africa where most trophy hunting takes place. Dulan's hunting grounds and all pastures are state-owned. Local herders have only long term leases of the land (commonly 50 years). As such the only people benefiting directly are those employed as guides drivers, all other benefits come from the government. Furthermore according to "Wild Animal Conservation Law of the People's Republic of China" (2018), the damage and losses caused by wildlife are mainly compensated by local governments. Hence we decided against using cost as a measure of individual WTP as in conventional economic applications for Choice Experiments in hunting context (Hanley et al., 2003). In terms of levels, we set 1,000 yuan / year / household as the upper limit for this attribute following discussion with local herders around the amount would be perceived to have a big impact on livelihoods and with wildlife managers on what could feasible should trophy hunting be restarted The levels below of $0,50,100,200,500$ yuan / year / household, were set to ensure linear growth. 
Table 1 Attributes and levels of a choice experiment on trophy hunting in China

\begin{tabular}{|c|c|c|}
\hline Attribute & Levels & Description \\
\hline \multirow{5}{*}{ Population change } & $-50 \%$ & \multirow{5}{*}{$\begin{array}{l}\text { Future change in population of blue } \\
\text { sheep compared to current level }\end{array}$} \\
\hline & $-10 \%$ & \\
\hline & 0 & \\
\hline & $+10 \%$ & \\
\hline & $+50 \%$ & \\
\hline \multirow[t]{2}{*}{ Trophy hunting } & Yes & \multirow[t]{2}{*}{ Method of wildlife management } \\
\hline & No & \\
\hline \multirow[t]{3}{*}{ Payment (Xining and Beijing) } & 0 Yuan & \multirow{6}{*}{$\begin{array}{l}\text { Xining and Beijing: Payment made by } \\
\text { the government per household per year } \\
\text { to local herders compensate for wildlife } \\
\text { damage Dulan: Compensation received } \\
\text { per household per year for wildlife } \\
\text { damage }\end{array}$} \\
\hline & 50 Yuan & \\
\hline & 100 Yuan & \\
\hline \multirow[t]{3}{*}{ Financial compensation (Dulan) } & 200 Yuan & \\
\hline & 500 Yuan & \\
\hline & 1000 Yuan & \\
\hline
\end{tabular}

Based on Table 1 we designed a pilot choice experiment using an orthogonal design formulated in SPSS v. 22.0 with the initial 49 choice alternatives being paired using a 'shifted technique' (Louviere, Hensher \& Swait, 2000) into 49 dichotomous choices. See the sample for the card in Table S1. These were then divided into seven sets, and individually administered to respondents (25 in Dulan, 29 in Xining and 25 in Beijing). Participants for the pilot were chosen opportunistically and were not considered in the final survey. The resultant data were analyzed using a multinomial logit (MNL) model and parameter estimates of the main effects were used as priors in a D-efficient Bayesian design implemented in Ngene 1.0.1 to design the final choice sets. Using 500 Halton draws from normal prior distributions for each parameter, we compared the mean Bayesian D-error of over 50,000 designs and selected the one with the lowest error at 0.085 . The resultant designs with 12 choice sets for each CE were then blocked into sets of six to reduce the time needed to complete a survey and any potential cognitive burden on the respondents. 


\section{Survey implementation}

Sampling in Xining and Beijing was carried out opportunistically in public locations with high foot traffic, with the explicit aim to equally represent all age classes and both genders. In Dulan, sampling first targeted nomadic households out in the pastures, but has this strategy did not yield a sufficient number of respondents $(n=40)$, we then targeted the nearest village, where we applied the survey to a member of every non-vacant household. Each survey started with an introduction about trophy hunting, its history in China in the context of blue sheep management, and finally an explanation of the different attributes to be considered in the choice experiment. The survey was administered through face-to-face interviews with the help of visual aids for the choice experiment section.

\section{Data Analysis}

We analyzed the data using LIMDEP NLOGIT 4.0. We first assessed the aggregate preferences of respondents using Random Parameter Logit (RPL) analysis. Although this model type allows for the investigating of how respondent characteristic impact preferences, it considers all respondents as a single group, which can obscure variations that are only evidence within smaller respondent sub-groups. These differences among sub-groups can be important when investigating issues such as trophy hunting which are highly polarized. To explore potential sub-group level heterogeneity in preferences, we used latent class modelling (LCM) (Boxall \& Adamowicz, 2002).

LCMs are a form of logistic regression based on the standard random utility model, considered to be the best approach to partition the sampled population into one or more homogeneous classes (Boxall \& Adamowicz, 2002). LMCs assume that respondents can be divided into a finite number of latent classes (or segments), based their preferences, and then aim to characterize each of those groups based on observable respondent characteristics, most commonly socio-demographic variables 
(e.g., gender, age, household income, education, ethnic group). It should be noted however that this characterization of respondents is always done in relation to a reference group and not in absolute terms.

LCM are estimated using maximum likelihood estimation and require that at the number of segments be set in advance. The optimal numbers of classes were identified based on a balanced assessment of statistics including Akaike Information Criteria (AIC) and Bayesian Information Criteria (BIC) (Birol, Karousakis \& Koundouri 2006) as well as the size of a class membership to avoid very small segments that have a higher probability of being spurious. We included an alternative specific constant (ASC) to account for the 'neither' responses. In all our analysis, ASC took a value of 1 when 'neither' choice was opted for, reflecting the utility derived from not choosing any of the offered choice options.

\section{Results}

We administered the survey to a total of 584 people who are willing to participate in, of which $556(95 \%)$ returned valid responses. These were divided as follows: 166 in Dulan, divided between the villages of Tuotuo $(n=87)$ and Xiumao (81), 201 in Xining and 189 in Beijing. The demographics of survey respondents in each of the three locations, can be found in Table S2.

\section{Attitudes towards wildlife management}

In terms of attitudes towards wildlife management, there was agreement across the three locations that wildlife should be managed to prevent species extinction (Fig. 1). Nonetheless, there were also statistically significant differences between the three locations, with Dulan residents being the most supportive, followed by Beijing and lastly Xining (Table S3). Support for hunting as management method to protect livelihoods was statistically higher in Dulan and similar in the two urban areas of Xining and Beijing (Table S3). This trend was similar when considering the need for 
meaningful benefit sharing with local communities, with rural residents being more supportive than urban ones, although in this case Beijing residents were significantly more supportive than those from Xining (Fig. 1; Table S3). There was opposition to the total protection for blue sheep, with respondents from Dulan being significantly less supportive of this measure than urban respondents, who were only weakly opposed to this measure (Fig. 1; Table S3). Lastly, there was support from rural residents for trophy hunting while urban residents were largely neutral about this practice (Fig. 1; Table S3).

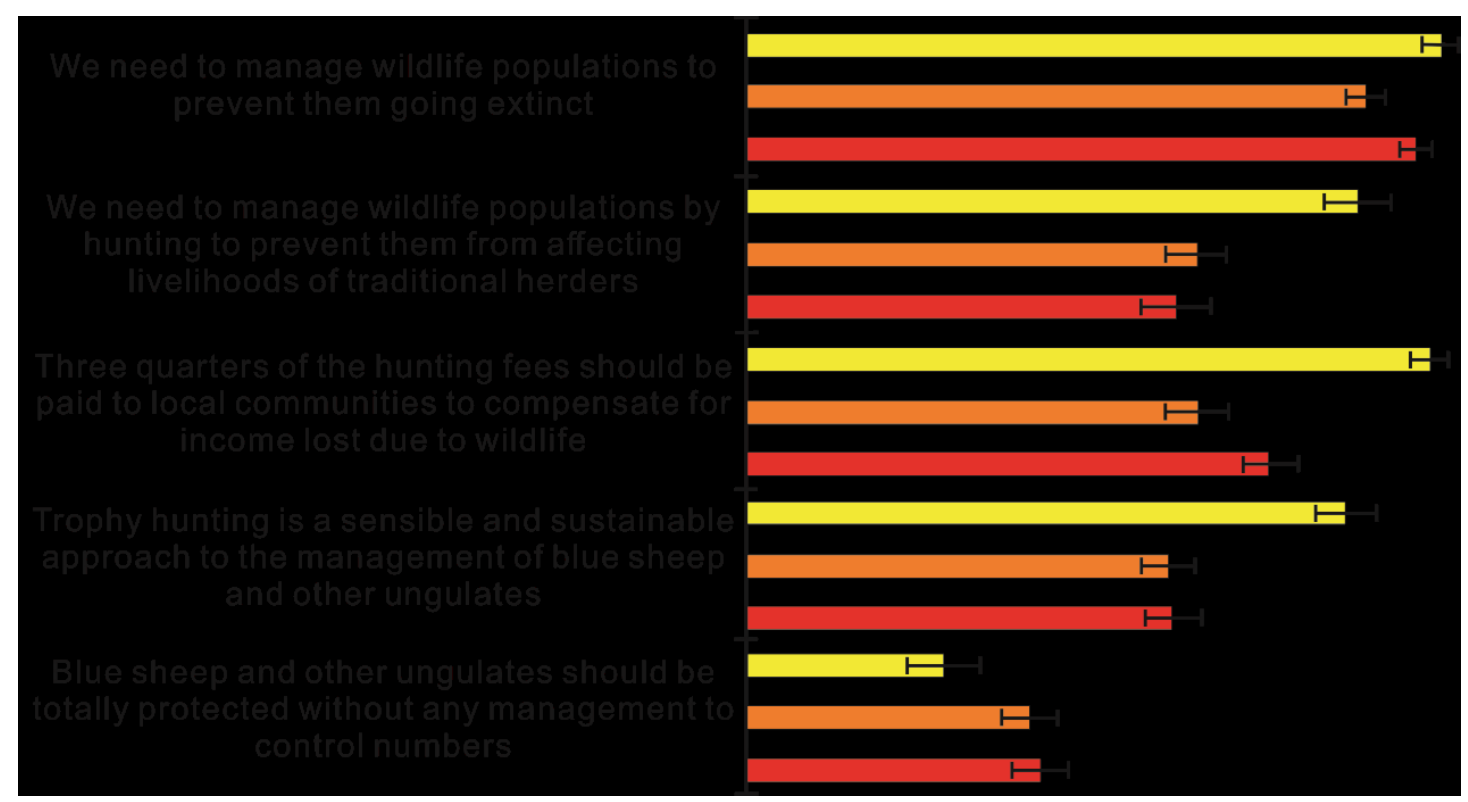

Figure 1 Mean attitude scores, with 95\% confidence intervals, of respondents from Dulan (yellow), Xining (orange) and Beijing (red) on wildlife management. 1='Very disagree'; 2='Disagree'; 3='No matter'; 4='Agree'; 5='Very agree'.

\section{Choice experiments}

We analyzed each region separately to be able to gain in-depth insights into the different trade-offs that people across the rural to urban continuum. In case of Xining and Beijing, the LCM had poor explanatory ability in terms of respondent segmentation, suggesting that variation between sub-groups was not significant (Supplementary Material Tables S4 to S7). As such we report here the result of the RPL, with the LCM results for these two locations in Supplementary Material. 


\section{Dulan}

The selected the LCM model with three respondent segments to describe the tradeoffs being made by participants in Dulan. This model was selected as it was the most parsimonious according to both the $\mathrm{BIC}$ and $\mathrm{AIC} 3$, the two most conservative criteria when it comes to the inclusion of additional variables, and which therefore favor the simplest model (Table 2).

Table 2 Summary of measures of model fit for Multinomial logit (MNL) and Latent Class Models (LCM) for Dulan International Hunting Area. The selected model is underlined.

\begin{tabular}{|l|l|l|l|l|l|}
\hline Model & $\mathbf{K}^{\mathbf{a}}$ & $\mathbf{L L}^{\mathbf{b}}$ & $\mathbf{A I C}^{\mathbf{c}}$ & BIC $^{\mathbf{d}}$ & AIC3 $^{\mathbf{e}}$ \\
\hline MNL & 7 & -903.6 & 1821.20 & 1855.53 & 1828.2 \\
\hline LCM2 & 20 & -808.27 & 1656.54 & 1754.61 & 1676.54 \\
\hline$\underline{\text { LCM3 }}$ & $\underline{33}$ & $\underline{-739.81}$ & $\underline{1545.62}$ & $\underline{1707.44}$ & 1578.62 \\
\hline LCM4 & 46 & -723.22 & 1538.44 & 1764.01 & 1584.44 \\
\hline LCM5 & 59 & -746.08 & 1610.16 & 1899.48 & 1669.16 \\
\hline
\end{tabular}

a Number of parameters.

${ }^{b}$ Log Likelihood.

${ }^{\mathrm{c}}$ Akaike's information criterion.

${ }^{\mathrm{d}}$ Bayesian information criterion.

${ }^{\text {e }}$ Modified Akaike's information criterion with 3 as penalty factor

Our model divided respondents in three groups of similar size. LCMs divide respondents into groups based their preferences and aim to then characterize those groups based on respondent characteristics, most commonly demographic variables. It should be noted however that this characterization of respondents is always done in relation to a reference group and not in absolute terms. LCM Segment 1 favored the status quo when it came to the population of blue sheep, and strongly opposed population decreases and trophy hunting. This segment was comparatively more likely to include wealthier households. Segment 2 also favored the status quo regarding blue sheep populations, opposing both decreases and strong increases in the populations. This segment supported trophy hunting, and was more likely to include respondents from wealthier households and villages with a Mongol ethic 
majority. The third and last segment also favored the status quo in relation to blue sheep populations, opposing any strong fluctuation in the population. This segment supports trophy hunting and was most likely to include poorer but more educated households.

Table 3 Multinomial logit (MNL) and Latent Class Model (LCM) estimates of utility function for each attribute, with standard errors for Dulan International Hunting Area.

Significance levels: $* \mathrm{P}<0.05, * * \mathrm{P}<0.01$. McFadden Pseudo R-squared $=0.321$.

Attribute reference levels: 'Population: no change', 'Without trophy hunting', 'Male',' Mongol village'

\begin{tabular}{|c|c|c|c|c|}
\hline Attribute levels & MNL & $\begin{array}{l}\text { LCM1 } \\
(36.6 \%) \\
\end{array}$ & \begin{tabular}{|l|} 
LCM2 \\
$(33.5 \%)$ \\
\end{tabular} & $\begin{array}{l}\text { LCM3 } \\
(29.9 \%)\end{array}$ \\
\hline ASC & $-1.964(0.246)^{\star *}$ & $\begin{array}{l}-4.948 \\
(0.944)^{* *}\end{array}$ & $-0.545(0.407)$ & $\begin{array}{l}-5.197 \\
(2.167)^{\star *}\end{array}$ \\
\hline Population: $-50 \%$ & $-1.393(0.218)^{* *}$ & $\begin{array}{l}-1.257 \\
(0.643)^{*}\end{array}$ & $\begin{array}{l}-2.112 \\
(0.377)^{\star *}\end{array}$ & $\begin{array}{ll}-3.364 & (1.791) \\
* & \\
\end{array}$ \\
\hline Population: $-10 \%$ & $-0.778(0.138)^{\star *}$ & $\begin{array}{l}-1.107 \\
(0.299)^{* *}\end{array}$ & $\begin{array}{l}-1.277 \\
(0.337)^{\star *}\end{array}$ & $-0.467(0.671)$ \\
\hline $\begin{array}{l}\text { Population: } \\
+10 \%\end{array}$ & $-0.493(0.197)^{\star *}$ & $\begin{array}{l}-0.593 \\
(0.453)\end{array}$ & $-0.493(0.387)$ & $-1.309(1.176)$ \\
\hline $\begin{array}{l}\text { Population: } \\
+50 \%\end{array}$ & $\begin{array}{ll}-1.260 & (0.267) \\
* * & \\
\end{array}$ & $\begin{array}{l}-0.743 \\
(0.819) \\
\end{array}$ & $\begin{array}{l}-1.087 \\
(0.401)^{* *}\end{array}$ & $\begin{array}{ll}-5.628 & (2.560) \\
* * & \\
\end{array}$ \\
\hline Trophy hunting & $0.502(0.101)^{\star *}$ & $\begin{array}{l}-0.732 \\
(0.238)^{\star *}\end{array}$ & $0.936(0.263)^{* *}$ & $3.139(0.797)^{\star *}$ \\
\hline $\begin{array}{l}\text { Government } \\
\text { subsidy }^{\mathrm{a}}\end{array}$ & $0.002(0.019)$ & $0.033(0.044)$ & $-0.006(0.045)$ & $0.012(0.064)$ \\
\hline \multicolumn{5}{|c|}{ Demographic segmentation } \\
\hline Gender & & $\begin{array}{l}-0.307 \\
(0.551) \\
\end{array}$ & $0.029(0.781)$ & \\
\hline $\mathrm{Age}^{\mathrm{b}}$ & & $\begin{array}{l}-0.120 \\
(0.224) \\
\end{array}$ & $0.420(0.442)$ & \\
\hline $\begin{array}{l}\text { Household } \\
\text { income }^{c}\end{array}$ & & $\begin{array}{l}0.526 \\
(0.251)^{\star *}\end{array}$ & $0.573(0.315)^{*}$ & \\
\hline Education & & $\begin{array}{l}-0.097 \\
(0.330) \\
\end{array}$ & $-0.287(0.405)$ & \\
\hline Ethnic group ${ }^{d}$ & & $\begin{array}{l}0.667 \quad(0.91 \\
0)\end{array}$ & $\begin{array}{l}-3.961 \\
(1.117) * *\end{array}$ & \\
\hline
\end{tabular}


a Unit used: $¥ 100$

${ }^{\text {b }}$ Categorized as $<18,19-25,26-35,36-50,>50$

${ }^{\circ}$ Categorized as $<¥ 5000$, $¥ 5000-¥ 7999$, $¥ 8000-¥ 10999$, $¥ 11000-¥ 13999$, $¥ 14000$ $¥ 16999, ¥ 17000-¥ 20000, \geq ¥ 20000$ annually

d Categorized as Mongol or Tibetan

\section{Xining}

Our results (Table 4) show that respondents from Xining also favored the status quo when it came to the number of blue sheep, specifically opposing any population decrease as well as a large increase in population. Respondents opposed trophy hunting, but believed herders in Dulan should be compensated financially for coexisting with blue sheep. Support for trophy hunting came mostly from better educated households.

Table 4 Random Parameter Logit estimates of utility function for each attribute, with standard errors for citizens of Xining, China. Significance levels: Significance levels:

$* \mathrm{P}<0.05, * * \mathrm{P}<0.01$. McFadden Pseudo R-squared $=0.362$. Attribute reference

levels: 'Population: no change', 'Without trophy hunting', 'Male'.

\begin{tabular}{|c|c|c|}
\hline Choice & Coefficient & Standard Error \\
\hline ASC & $-2.774^{\star * *}$ & 0.258 \\
\hline Population: $-50 \%$ & $-2.356^{* * *}$ & 0.275 \\
\hline Population: $-10 \%$ & $-1.033^{* * *}$ & 0.166 \\
\hline Population: $+10 \%$ & -0.062 & 0.207 \\
\hline Population: $+50 \%$ & $-1.721^{* * *}$ & 0.274 \\
\hline Trophy hunting & $-2.707^{* * *}$ & 0.527 \\
\hline Government subsidy ${ }^{a}$ & $0.148^{* \star *}$ & 0.035 \\
\hline Trophy hunting *Gender & -0.005 & 0.167 \\
\hline Trophy hunting *Age ${ }^{\mathrm{b}}$ & 0.038 & 0.061 \\
\hline $\begin{array}{l}\text { Trophy hunting *Household } \\
\text { income }^{c}\end{array}$ & -0.022 & 0.052 \\
\hline Trophy hunting *Education & $0.3149^{\star * *}$ & 0.098 \\
\hline
\end{tabular}

a Unit used: $¥ 100$

${ }^{\text {b }}$ Categorized as $<18,19-25,26-35,36-50,>50$ 
${ }^{\circ}$ Categorized as $<¥ 20000, ¥ 20000-¥ 39999, ¥ 40000-¥ 59999, ¥ 60000-¥ 79999$, $¥ 80000$ $¥ 99999, ¥ 100000-¥ 119999, \geq ¥ 120000$ annually

\section{Beijing}

As shown in the Table 5, residents of Beijing rejected any change to the status quo when it came to blue sheep population. This group opposed trophy hunting and believed herders should be financially compensated by coexisting with blue sheep. These support for trophy hunting were largely associated with younger male respondents.

Table 5 Random Parameter Logit estimates of utility function for each attribute, with standard errors for citizens of Beijing, China. Significance levels: Significance levels:

$* \mathrm{P}<0.05, * * \mathrm{P}<0.01$. McFadden Pseudo R-squared $=0.207$. Attribute reference

levels: 'Population: no change', 'Without trophy hunting', 'Male'.

\begin{tabular}{|c|c|c|}
\hline Choice & Coefficient & Standard Error \\
\hline ASC & $-1.676^{\star * \star}$ & 0.215 \\
\hline Population: $-50 \%$ & $-2.110^{* * *}$ & 0.236 \\
\hline Population: $-10 \%$ & $-0.642^{\star * \star}$ & 0.153 \\
\hline Population: $+10 \%$ & $-0.469^{\star *}$ & 0.190 \\
\hline Population: $+50 \%$ & $-1.173^{\star * \star}$ & 0.229 \\
\hline Trophy hunting & -0.682 & 0.520 \\
\hline Government subsidy $^{a}$ & $0.085^{\star * *}$ & 0.029 \\
\hline Trophy hunting *Gender & $-0.411^{* *}$ & 0.171 \\
\hline Trophy hunting *Age ${ }^{b}$ & $-0.283^{* * *}$ & 0.060 \\
\hline $\begin{array}{l}\text { Trophy hunting } \\
{ }^{*} \text { Household income }{ }^{c}\end{array}$ & -0.022 & 0.054 \\
\hline Trophy hunting *Education & -0.083 & 0.074 \\
\hline
\end{tabular}

a Unit used: $¥ 100$

${ }^{\text {b } C a t e g o r i z e d ~ a s ~}<18,19-25,26-35,36-50,>50$

c Categorized as $<¥ 20000, ¥ 20000-¥ 39999$, $¥ 40000-¥ 59999$, $¥ 60000-¥ 79999$, $¥ 80000$ $¥ 99999, ¥ 100000-¥ 119999, \geq ¥ 120000$ annually

\section{Discussion}

This research showcases how preferences for wildlife management options can vary 
not only across an urban to rural continuum, but also across demographic and cultural lines. Our discussion focuses on how our research can inform and support the development of conservation policy based on an objective understanding of the preferences of local stakeholder groups as well as the general public.

\section{The urban and rural contrast}

Our results reveal a gap between urban and rural dwellers. In attitudinal terms, responses to all five statements were found to have statistically significant differences between respondents in rural Dulan and those of urban Xining and Beijing. Statistically significant differences were only established for two of the five statements when residents of Xining and Beijing are compared (Fig. 1, Table S3). These differences are reflected in the choices for the management of blue sheep. While both urban and rural residents favor maintaining the status quo when it comes to the population size of blue sheep, urban residents (Table 4 and 5) were mostly against trophy hunting whereas local communities supported trophy hunting (Table 3). Nevertheless, it should be highlighted that there was overall the least agreement with the total protection for blue sheep with management than for any other proposition, including the use of trophy hunting (Fig. 1).

It is worth highlighting however that at the local community level there was heterogeneity in management preferences, with about a third of respondents opposing trophy hunting. This group, composed largely of wealthier respondents was also the only one that did not oppose a strong increase in blue sheep population, which suggests this group may not be dependent on livestock grazing for their livelihood. Ethnicity was also a key characteristic in one of the respondent segments, suggesting that respondents from villages with the majority Mongol ethnic group most supportive of trophy hunting. The majority support for trophy hunting in Dulan was surprising given that the practice has not taken place for a decade and there were 
some unhappiness with the benefit sharing mechanism that was in place. In other regions where trophy hunting had been practiced, local support decreased quickly after the economic benefits stopped flowing to the local economy (Nordbo, Turdumambetov \& Gulcan, 2018). During the survey in Dulan, we learned that the hunting guide or porter directly obtained economic benefits from trophy hunting. The hunters would give each guide or porter a tip of up to one thousand USD after the hunt was completed. This was a significant source of income, compared to the average annual income (around 1000 USD), but only a few people benefited from these guiding activities. The official fees from trophy hunting were paid to the government with very little trickling down to the local community level. The benefit sharing mechanisms within local communities would therefore need to be improved, and this likely explains why respondents in Dulan did not show a preference for receiving a government subsidy (Table 3 ), as historically governmental efforts to improve the benefits received by local communities have been to some extent ineffective.

In terms of the urban respondents (Table 4 and 5), it is worth highlighting how there was no clear support for any particular blue sheep population size, with the focus being the rejection of trophy hunting as a practice. In Xining and Beijing the minority group supporting trophy hunting was not homogenous, making it hard to establish links between demographic profile and support for trophy hunting in China. It is possible that psychographic factors play a bigger role in determining this support, something that should be investigated in future research.

\section{Giving locals a voice}

The debate around the merits and pitfalls of trophy hunting has lasted now for nearly a century (Adams, 2009). Nevertheless, the discussion, both within and outside academic, has thus far been dominated by western views and values (Angula et al., 2018). Particularly rare have been studies that aim to capture the perspective of 
citizens of the countries where trophy hunting is taking place, in particular those communities living with wildlife, with (Yasuda, 2011; Angula et al., 2018; Nordbo et al., 2018) being important exceptions. These studies have often revealed important gaps between constituencies in the West which have largely lobbied for to end or restrict trophy hunting, including through bans on the importation of hunting trophies (Cooney, 2017; Angula et al., 2018), and the views of those people living with the wildlife, which as with our study largely support trophy hunting (Yasuda, 2011; Angula et al., 2018; Zafra-Calvo \& Moreno-Penaranda, 2018). Future debates and policy processes need do more to include the perspectives of under-represented groups in conservation who may not share the views of those in more powerful positions (Sandbrook et al., 2019).

People are likely to live with wildlife only when they receive benefits that offset or indeed surpass the costs of doing so (Cooney et al., 2017; Störmer et al. 2019). The current Chinese policy on trophy hunting is consistent with the preferences of urban citizens but opposed to the preferences of the majority of people sharing the land with the wildlife to be conserved. This disparity is likely due to the fact that rural inhabitants often face unsurmountable barriers when trying to influence policy processes or simply making their voices heard in public fora such as social media (Angula et al., 2018). These barriers come in many shapes, from the lower education level and income that most rural households have when compared to urban residents, to the access to the technological platforms where many of these discussions take place, such as social media. It is therefore not surprising that the voices of Dulan residents were not part of the 2006 and 2011 debates around the reopening of trophy hunting in China, which meant that only those with little to lose where able to influence the policy process, thus keeping trophy hunting from reopening.

Wildlife conservation requires funding to be effective and sustainable but often 
imposes crippling costs to governments and local communities living alongside wildlife (Barua, Bhagwat \& Jadhav, 2013; Zafra-Calvo \& Moreno-Penaranda, 2018). Wildlife viewing is often heralded as one alternative to consumptive uses of wildlife but is not always suitable for a landscape, particularly where wildlife densities are low, and in places such as the Tibetan plateau, where the location is challenging due remoteness and high altitude and a degree of political instability (Lindsey et al., 2012). Furthermore wildlife tourism has a much greater need for infrastructure and personal, which together with it involving a much larger number of tourism means it has a much higher environmental footprint that recreational hunting (Di Minin, Leader-Williams \& Bradshaw, 2016). Thus trophy hunting should be considered as a additional way to ensure the sustainable management of wild ungulates in QinghaiTibet Plateau, a remote region with a low but growing population density and livelihoods that are deeply linked to livestock grazing (Liu, 1993).

The Chinese government's current policy to development is to encourage herders to lease their traditional pastures and manage grazing through the large-scale erection of livestock fences (You et al., 2013). This policy is highly contested and one major drawback is that wild ungulates will be excluded from the enclosures (Tsering, 2009). This enclosure process is perceived by government as key to improving local living standards, particularly in the absence of other income sources but in the longer term it is likely to become a substantial cause of mortality for blue sheep due to entanglement, predation and loss of grazing (You et al., 2013). Lastly, fences are likely to close off migration paths for ungulates with potential sever consequences for the ungulates of the Qinghai-Tibet Plateau (You et al., 2013).

The resumption of trophy hunting in Dulan would provide an opportunity to assess an alternative 'free-range' model of sustainable grassland management. If carefully managed in ecological and social terms to avoid the mistakes of the past on the Qinghai-Tibet Plateau (Jiang et al., 2012) and on other countries across Central Asia (Nordbo et al., 2018), one key aspect for delivering sustainability would be the 
introduction of an efficient and equitable benefit sharing model (Cooney, 2017) that allow more locals, rather than a few hunting guides, to directly obtain economic benefits from Blue Sheep trophy hunting and thus would be a key factor in obtaining community support.

As a conservation tool, trophy hunting is contentious and polarized issue, that transcends the topic of biodiversity conservation and overlaps with animal welfare and personal values and ethics (Lindsey et al., 2016). However, our research has shown that a deeper understanding of how trophy hunting can be used as a valuable component of a sustainable wildlife management strategy if it focuses on rural livelihoods and benefit sharing. It is therefore important that researchers and policy makers engage in evidence-based debates that are informed by both biological and human considerations, particularly those that concern the people living alongside wildlife and the governments that bear the cost of conserving biodiversity.

\section{Acknowledgments}

This work was supported by the research program from China's State Forestry Grass Administration and by the Fundamental Research Funds for the Central Universities, (2572019DA02). We also would like to thank Xiaotong Wan, Chang Shu, Qiangfei Zhao and Yonghong Shi for their assistance in the field.

\section{References}

Adams, W.M. (2009). Sportsman's shot, poacher's pot: hunting, local people and the history of conservation. In: Recreational hunting, conservation and rural livelihoods: science and practice:127-140. Dickson, B., Hutton, J., Adams, W.M.(Eds). UK: Wiley-Blackwell.

Angula, H.N., Stuart-Hill, G., Ward, D., Matongo, G., Diggle, R.W. \& Naidoo, R. (2018). Local perceptions of trophy hunting on communal lands in Namibia. Biol. Conserv. 218, 26-31.

Barua, M., Bhagwat, S.A. \& Jadhav, S. (2013). The hidden dimensions of humanwildlife conflict: health impacts, opportunity and transaction costs. Biol. Conserv. 157, 309-316.

Bauer, H., Chardonnet, B., Jones, M. \& Sillero-Zubiri, C. (2019). Trophy hunting: Broaden the debate. Science. 366, 433-434. 
Birol, E., Karousakis, K. \& Koundouri, P. (2006). Using a choice experiment to account for preference heterogeneity in wetland attributes: The case of Cheimaditida wetland in Greece. Ecol.Econ. 60, 145-156.

Boxall, P.C. \& Adamowicz, W.L. (2002). Understanding heterogeneous preferences in random utility models: a latent class approach. Environ. Resour. Econ. 23, 421446.

Brown, A.A., Dean, A.J., Possingham, H. \& Biggs, D. (2019). The role of animal welfare values in the rhino horn trade debate. Conserv. Sci. Pract. 11, e103.

Bullock, C.H., Elston, D.A. \& Chalmers, N.A.(1998). An application of economic choice experiments to a traditional land use-deer hunting and landscape change in the Scottish Highlands. J. Environ. Manage. 52(4), 335-351.

Cao, S., Zhou, X. \& Zhang, W. (2014). Role of modern hunting in wildlife management. Chinese. J. Appl. Ecolo. 25, 297-304.

Chaukura, I., Satau, G., Lubilo, R. \& Nathinge, N.H. (2020). Communities response. Highwire Comment Response to: Trophy hunting: Bans create opening for change. Available at https://science.sciencemag.org/content/366/6464/434/tab-e-letters

Cooney, R. (2017). African voices are missing from the elephant trophy debate. The Washington Post, Washington.

Cooney, R., Freese, C., Dublin, H., Roe, D., Mallon, D., Knight, M., Emslie, R., Pani, M., Booth, V., Mahoney, S. \& Buyanaa, C. (2017). The baby and the bathwater: trophy hunting, conservation and rural livelihoods. Unasylva. 68, 249.

Crosmary, W.G., Loveridge, A.J., Ndaimani, H., Lebel, S., Booth, V., Côté, S.D. \& Fritz, H. (2013). Trophy hunting in Africa: long-term trends in antelope horn size. Anim. Conserv. 16, 648-660.

Di Minin, E., Leader-Williams, N. \& Bradshaw, C.J.A. (2016). Banning trophy hunting will exacerbate biodiversity loss. Trends. Ecol. Evol. 31, 99-102.

Hanley, N.D., MacMillan, D.C., Wright, R.E. \& Patterson, I. (2003). Economics and the Design of Nature Conservation Policy: A Case Study of Wild Goose Conservation in Scotland Using Choice Experiments. Anim. Conserv. 6, 123129.

Harihar, A., Veríssimo, D. \& MacMillan, D.C. (2015). Beyond compensation: integrating local communities' livelihood choices in large carnivore conservation. Global. Environ. Chang. 33, 122-130.

Harris, R.B. (Ed). (2008). Trophy hunting: opportunities squandered. In Wildlife conservation in China: preserving the habitat of China's wild west. New York: M.E. Sharpe.

Heqin, W. (2016). The rapid restoration of the number of Tibetan antelopes in China has caused pressure and damage to regional grasslands. Beijing: China News Service. 
International Union for the Conservation of Nature Species Survival Commission. (2012). IUCN SSC Guiding principles on trophy hunting as a tool for creating conservation incentives. Ver. 1.0. IUCN, Gland.

Jiang, Z., Li, C., Jenkins, R.W.G. \& Zheng, J. (2012). International trophy hunting in China. Oryx. 46, 173.

Lazarsfeld, P.F. \& Henry, N.W. (1968). Latent structure analysis. Houghton Mifflin. New York.

Houghton M.C., Lindsey, P.A., Balme, G.A., Booth, V.R. \& Midlane, N. (2012). The significance of African lions for the financial viability of trophy hunting and the maintenance of wild land. PloS. one. 7, e29332.

Lindsey, P.A., Balme, G.A., Funston, P.J., Henschel, P.H. \& Hunter, L.T.B. (2016). Life after Cecil: channelling global outrage into funding for conservation in Africa. Conserv. Lett. 9, 296-301.

Liu, Y. (1993). International hunting and the involvement of local people, Dulan, Qinghai, People's Republic of China. MSc thesis, University of Montana.

Louviere, J.J., Hensher, D.A. \& Swait, J.D. (2000). Stated choice methods: analysis and applications. Cambridge: Cambridge university press.

Macdonald, D.W., Jacobsen, K.S., Burnham, D., Johnson, P.J. \& Loveridge, A.J. (2016). Cecil: a moment or a movement? Analysis of media coverage of the death of a lion, Panthera leo. Animals. 6, 26.

Macdonald, D.W., Loveridge, A.J., Dickman, A., Johnson, P.J., Jacobsen, K.S. \& Du Preez, B. (2017). Lions, trophy hunting and beyond: knowledge gaps and why they matter. Mammal. Rev. 47, 247-253.

MacMillan, D.C. (2004). Tradeable Deer obligations - a cost-effective answer to too many deer? J. Environ. Manage. 71(3), 261-270.

MacMillan, D.C. \& Leitch, K. (2008). Conservation with a gun: understanding landowner attitudes to deer hunting in the Scottish Highlands. Hum. Ecol. 36, 473-484.

MacMillan, D.C., Leitch, K., Wightman, A. \& Higgins, P. (2010). The management and role of Highland sporting estates in the early 21st Century: the owner's view of a unique but contested form of land use. Scot. Geogr. J. 126(1), 24-40.

Naidoo, R., Weaver, L.C., Diggle, R.W., Matongo, G., Stuart-Hill, G. \& Thouless, C. (2016). Complementary benefits of tourism and hunting to communal conservancies in Namibia. Conserv. Biol. 30,628-638.

NDRC (National Development and Reform Commission). (1996). China Population, Resources and Environment Report. Beijing: China Environmental Science Press.

NEPA (National Environmental Protection Agency). (2002). China Ecological Environment Report. Beijing: China Environmental Science Press. 
Nordbo, I., Turdumambetov, B. \& Gulcan, B. (2018). Local opinions on trophy hunting in Kyrgyzstan. J. Sustain. Tour. 26, 68-84.

Qinghai Provincial Bureau of Statistics. (2017). Qinghai Statistical Yearbook 2017. National Bureau of Statistics of China Survey Office in Qinghai, Beijing: China Statistics Press.

Sandbrook, C., Fisher, J.A., Holmes, G., Luque-Lora, R. \& Keane, A. (2019). The global conservation movement is diverse but not divided. Nat. Sustain. 2, 316-323.

Störmer, N., Weaver, L.C., Stuart-Hill, G., Diggle, R.W. \&Naidoo R. (2019). Investigating the effects of community-based conservation on attitudes towards wildlife in Namibia. Biol. Conserv. 233, 193-200.

Subroy, V., Rogers, A.A. \& Kragt, M.E. (2018). To Bait or Not to Bait: A Discrete Choice Experiment on Public Preferences for Native Wildlife and Conservation Management in Western Australia. Ecol. Econ. 147, 114-122.

Trenkel, V.M. (2001). Exploring red deer culling strategies using a population-specific calibrated management mode. J. Environ. Manage. 62(1), 37-53.

Tsering, D. (2009). Grassland privatization and fencing project and its impacts on nature reserve and wildlife protection in the Chang Tang Regions of Tibet, China. Tibetan Studies. 3, 85-93.

Veríssimo, D., Pongiluppi, T., Santos, M.C.M., Develey, P.F., Fraser, I., Smith, R.J. \& MacMilan, D.C. (2014). Using a systematic approach to select flagship species for bird conservation. Conserv. Biol. 28, 269-277.

Wang, C., Zhang, W. \& Zhang, C. (2006). Fence and Gun - Debate on Wildlife Protection. China. Ec. Weekly. 26-27.

Wielgus, R.B., Morrison, D.E., Cooley, H.S. \& Maletzke, B. (2013). Effects of male trophy hunting on female carnivore population growth and persistence. Biol. Conserv.167, 69-75.

Yasuda, A. (2011). The Impacts of Sport Hunting on the Livelihoods of Local People: A Case Study of Benoue National Park, Cameroon. Soc. Natur. Resour. 24, 860869.

You, Z., Jiang, Z., Li, C. \& Mallon, D. (2013). Impacts of grassland fence on the behavior and habitat area of the critically endangered Przewalski's gazelle around the Qinghai Lake. Chinese. Sci. Bull. 58, 2262-2268.

Zafra-Calvo, N. \& Moreno-Penaranda, R. (2018). Exploring local people's views on the livelihood impacts of privately versus community managed conservation strategies in the Ruvuma landscape of North Mozambique-South Tanzania. J. Environ. Manage. 206, 853-862. 